\title{
The Evaluation Index System of Innovation-Driven Capability of Chinese Manufacturing Industry Based on Factor Analysis
}

\author{
Chuhao Zhao ${ }^{1}$, Shanling $\mathrm{Liao}^{2}$ and Jinfa $\mathrm{Li}^{3}$ \\ ${ }^{1}$ Chinese Academy of Governance, Beijing 100089, China \\ ${ }^{2}$ Guangxi Normal University, Guangxi 541006, China \\ ${ }^{3}$ School of Management Engineering, Zhengzhou University, Zhengzhou 450001, China
}

\begin{abstract}
In China's new normal, a strategy named "Made in China 2025" was proposed to speed up the manufacturing's transformation and upgrading. The hardship of China's manufacturing industry transformation and upgrading are the limit capability of independent innovation, the complexity and variability for competitive environment and the existence of institutional hurdles. At present, China is facing the powers of the industry from manufacturing to major, The paper will use factor analysis method to construct the evaluation index system of innovation-driven ability of Chinese manufacturing industry, and established evaluation model of innovation-driven ability of Chinese manufacturing industry. Based on the analysis of the model, the paper will propose the innovation driving strategy to speed up manufacturing transformation and upgrading.
\end{abstract}

Key words. Innovation-Driven, Manufacturing Industry, Factor Analysis.

\section{Introduction}

At present, China's manufacturing industry is featured by innovation ability insufficiency, low level of industrial structure, high resource consumption, low quality and efficiency. The popularization and the promotion of cloud computing, Internet of things, big data and intelligence engineering pose great pressures to China's manufacturing industry. The rapid development of information technology and mobile Internet technology promotes the change of industry. Moreover, with the China's economy coming into the new normal, the domestic manufacturing industry is faced with tremendous pressures from industrial transformation and upgrading, as well as the industrial competition caused by the reindustrialization of developed countries. Therefore, it is essential to implement the innovation driven strategy, which is a fundamental way to break through the bottleneck of China's economic development and solve the deep-seated contradictions and problems. The strategy is related to the future and destiny of the Chinese nation.

In 1982, Nelson and Winter published "the evolutionary theory of economic change", which made a ground-breaking contribution to apply the theory and method of evolutionary economics to study technology innovation. Based on the idea of evolution, Nalsonit concluded that innovation was a process of learning, searching, and (social) selection. In addition, Anderson and Tushman (1990) put forward the concept of "technology life cycle" to describe the speed of innovation relative to the technological development stage. Subsequently, Silverberg, Dosi and Orsenigo (1998) made a systematic analysis of the multidimensional structure and behaviour of variability within the technology innovation and diffusion system by building the dynamic evolution model of technology innovation. Moreover, Niosi and Banik (2005) analysed the evolution process of technological innovation in 90 biotechnology companies and demonstrated that the complex process of the evolution of biological technology innovation presented the three stage evolution law of " $R$ \& $D$ organization innovation- enterprise innovation -regional technology innovation".

In summary, scholars at home and abroad have conducted relatively abundant researches about innovation driven models with diversified methods. However, the majority of the existing researches are carried out from the macroscopic aspect, with focus on the choice of technology innovation to enhance manufacturing industry, only taking the technology innovation as a countermeasure to promote competitiveness of manufacturing industries and enterprises. There is a lack of general rules in the innovation driven interior to study the development of manufacturing industry. Furthermore, the current domestic research is inadequate in the exploration of some quantitative law in the manufacturing technology innovation system.

On the basis of previous researches, this article took the problems faced by China in the innovation driven process as objectives and established the applicable evaluation index system for the innovation driven ability of manufacturing industry in China and developing countries. In addition, it tried to make the measurement scale and tools for the innovation driven ability of China's manufacturing industry. Moreover, using factor analysis to evaluate the innovation driven ability of China's manufacturing industry, a foundation has been laid for the further empirical research, so as to take the development countermeasures to improve the innovation driven ability of China's manufacturing industry. 


\section{Innovation-driven Strategy - -The Core Motive Force of the Transformation and Upgrading of China' s Manufacturing Industry}

Currently, the Chinese government is appealing for the implementation of innovation-driven development strategy, emphasizing on using scientific and technological innovation to improve social productivity and comprehensive national strength, which places the scientific and technological innovation in the core position of national development. The innovation-driven strategy has become the major strategic choice in response to the China's economic growth shift and structural adjustment pains as well as the pre-stimulating preparation for the digestion period of the new era, in order to create a new China's economic upgrading version. Manufacturing industry is the foundation of comprehensive national strength, and an important strategic industry to maintain stable growth of national economy and solve employment problems. It is an important material carrier for China's construction of an innovation-oriented country and plays a pivotal role in China's economic development. Innovation-driven strategy is the necessity of for the expansion of the global manufacturing industry chain. It is the main engine to drive the transformation and upgrading of China's manufacturing industry and the key measure to realize the transition from "Made in China" to "Created in China".

\section{The Predicament Innovation-Driven in the Transformation and Upgrading of Manufacturing Industry in China}

In the new normal, the innovation driven transformation and upgrading of manufacturing industry in China is a necessary option to build the competitive advantage for manufacturing industry, which is conducive to consolidating and enhancing the international status of China's manufacturing industry. China's economy has begun to enter the new stage of speed shifting and economic restructuring. It not only means a slowdown in economic growth, but also suggests the change of economic growth momentum and the transformation of economic development. At present, China's manufacturing enterprises are in the "climbing plateau", so that the innovation-driven transformation and upgrading of manufacturing industry will face a series of restricting factors in the short term.

\subsection{Lack of Independently Innovative Ability among Manufacturing Enterprises}

The biggest problem faced by China's manufacturing industry is the lack of independent innovation ability and the development system combining original innovation and integrated innovation. Statistically, in large and medium-sized industrial enterprises, only $28.3 \%$ of them carry out researching activities and only $27.6 \%$ of them have established researching institutions, with researchers only accounting for $3.3 \%$ of total employees. It can be found that the engagement in research of enterprises is far from enough. At the same time, influenced by the conversion of original industry research institutes, the common technology research of industrial system is weakened, and the technologically sustained input to the innovation becomes inadequate, which further restricts the improvement of the manufacturing enterprises' ability of independent innovation.

Table 1. National Technical Innovation Model.

\begin{tabular}{|c|c|c|}
\hline & $\begin{array}{c}\text { Research And } \\
\text { Development } \\
\text { Model }\end{array}$ & $\begin{array}{c}\text { Production- } \\
\text { Education-Research } \\
\text { Model } \\
\text { Numbering }\end{array}$ \\
\hline $\begin{array}{l}\text { Silicon } \\
\text { Valley }\end{array}$ & $\begin{array}{l}\text { From basic research } \\
\text { to applied research } \\
\text { and development, } \\
\text { mainly for original } \\
\text { innovation }\end{array}$ & $\begin{array}{c}\text { Represented by } \\
\text { Stanford university } \\
\text { research institutions } \\
\text { is the model of close } \\
\text { combination }\end{array}$ \\
\hline $\begin{array}{l}\text { Taiwan } \\
\text { Hsinchu }\end{array}$ & $\begin{array}{c}\text { Development model } \\
\text { is priority to product } \\
\text { application } \\
\text { technology, } \\
\text { integrated } \\
\text { innovation and } \\
\text { secondary } \\
\text { innovation }\end{array}$ & $\begin{array}{l}\text { Research institutes } \\
\text { have a remarkable } \\
\text { effect on innovation, } \\
\text { especially the } \\
\text { industrial technology } \\
\text { research institute }\end{array}$ \\
\hline $\begin{array}{l}\text { Bangalore, } \\
\text { India }\end{array}$ & $\begin{array}{l}\text { Application } \\
\text { software } \\
\text { development }\end{array}$ & $\begin{array}{l}\text { Indian institute of } \\
\text { technology university } \\
\text { and other research } \\
\text { institutions, } \\
\text { enterprises have built } \\
\text { a close cooperate } \\
\text { relationship }\end{array}$ \\
\hline $\begin{array}{c}\text { Zhonggu- } \\
\text { Ancun }\end{array}$ & $\begin{array}{l}\text { Mainly on basic } \\
\text { research, at the }\end{array}$ & $\begin{array}{c}\text { The university is the } \\
\text { major power of }\end{array}$ \\
\hline
\end{tabular}




\begin{tabular}{|c|c|c|}
\hline & $\begin{array}{c}\text { same time paying } \\
\text { attention to the } \\
\text { transformation of } \\
\text { achievements }\end{array}$ & $\begin{array}{c}\text { technology } \\
\text { innovation }\end{array}$ \\
\hline
\end{tabular}

\subsection{Discontinuities Existing in the Support Power of Transformation and Upgrading of Manufacturing}

Since China's reform and opening up, China's manufacturing industry has been dependent on the developed countries in technologies, and is taken as the product assembly line in a very long time. However, the advantages of "industrial chain" and "culture industry" consciousness have still not been accumulated and matured in the national economic and social development. In the past few decades, there were sufficient preferential policies, lands and labors, which provided a key content in comparative advantage for manufacturing industry in China to catch up with the global trend. But it is worth noting that the extensive development mode of manufacturing industry has not been fundamentally changed, and the pressure generated by population, resources and environment is more and more prominent.

\subsection{The External Environment Manufacturing Industry Facing is Complicated}

Since the outbreak of the 2008 international financial crisis, developed countries have implemented the strategy of "reindustrialization" and "returning of manufacturing industry", which brings many restrictions or domestic manufacturing industry on the market and technology. At the same time, attracted by the low cost, many industrialized countries transfer their mid-range products processing and manufacturing industries to those low and middle-income countries, which form relatively fierce competitions with China, leading up to the besieged position of demotic manufacturing industry. As entering the late stage of industrialization, market demand is declining, resulting in the highly excess of the traditional capacity. Therefore, the pressure from market is mainly focused on the demand of saturated low-end products.

\section{Evaluation Method of Innovation Driving Capability of Chinese Manufacturing Industry}

It is necessary to collect a large number of indicators (variables) in the study of China's manufacturing innovation driving ability evaluation, which is beneficial for extracting useful information. However, there may be some correlations among these variables; the extracted information will be repeated and invalid. Factor analysis is to maximize the preservation of the original information in the case, with a few factors to describe the original number of indicators or observations between the data relationship. Factor analysis can classify these closely related variables as a unit, reducing the number of factors to reflect the original data contained in the information.

\subsection{Evaluation index}

On the basis of the existing research, this paper constructs the evaluation index system of Chinese manufacturing innovation drive ability. The index system of this paper mainly revolves around the goal of innovation ability, which can be divided into five parts, namely innovation human input, innovation financial input, innovation main input, innovation technology output and innovation diffusion, and 23 sub-indexes.

Table 2. Evaluation Index System of Innovation Capability of Chinese Manufacturing Industry

\begin{tabular}{|c|c|c|c|}
\hline $\begin{array}{l}\text { targets } \\
\text { (A) }\end{array}$ & $\begin{array}{c}\text { Main } \\
\text { indicators } \\
\text { (B) }\end{array}$ & Second indicators $(\mathrm{C})$ & \\
\hline \multirow{11}{*}{$\begin{array}{c}\text { Innovation } \\
\text { ability } \\
\text { (A) }\end{array}$} & \multirow{5}{*}{$\begin{array}{c}\text { Manpower } \\
\text { (B1) }\end{array}$} & The number of senior titles & $\mathrm{C} 1$ \\
\hline & & R \& D personnel & $\mathrm{C} 2$ \\
\hline & & $\begin{array}{c}\text { Number of returned overseas } \\
\text { students }\end{array}$ & $\mathrm{C} 3$ \\
\hline & & $\begin{array}{l}\text { Scientific and technological } \\
\text { activities personnel }\end{array}$ & $\mathrm{C} 4$ \\
\hline & & College or above & $\mathrm{C} 5$ \\
\hline & \multirow{5}{*}{$\begin{array}{l}\text { Funding } \\
\text { (B2) }\end{array}$} & R\& d expenditure & C6 \\
\hline & & $\begin{array}{c}\text { Total government finance } \\
\text { expenditure }\end{array}$ & $\mathrm{C} 7$ \\
\hline & & $\begin{array}{l}\text { financial science and } \\
\text { technology funds }\end{array}$ & $\mathrm{C} 8$ \\
\hline & & fixed investments & C9 \\
\hline & & Investment in infrastructure & $\mathrm{C} 10$ \\
\hline & Innovation & Number of high - tech & $\mathrm{C} 11$ \\
\hline
\end{tabular}




\begin{tabular}{|c|c|c|c|}
\hline \multirow{4}{*}{$\begin{array}{c}\text { system } \\
\text { (B3) }\end{array}$} & $\begin{array}{c}\text { Number of incubation } \\
\text { enterprises }\end{array}$ & $\mathrm{C} 12$ \\
\cline { 3 - 4 } & & $\begin{array}{c}\text { Number of R \& D } \\
\text { Institutions }\end{array}$ & $\mathrm{C} 13$ \\
\cline { 3 - 4 } & & $\begin{array}{c}\text { Number of Innovation } \\
\text { Service Organizations }\end{array}$ & $\mathrm{C} 14$ \\
\cline { 3 - 4 } & $\begin{array}{c}\text { Number of Patent } \\
\text { Applications }\end{array}$ & $\mathrm{C} 15$ \\
\hline \multirow{4}{*}{$\begin{array}{c}\text { Output } \\
\text { (B4) }\end{array}$} & Product sales revenue & $\mathrm{C} 16$ \\
\cline { 3 - 4 } & & Technical income & $\mathrm{C} 17$ \\
\cline { 3 - 4 } & & Total Labor Productivity & $\mathrm{C} 18$ \\
\hline
\end{tabular}

\subsection{Model Setup}

With X_P representing the evaluation index of innovation capability of China's manufacturing industry. In each of the $p$ economic variables, each variable contains $\mathrm{m}$ aspects of the evaluation, which are called the common factors of $\mathrm{p}$ economic variables. In the various economic variables, $\mathrm{m}$ common factor cannot explain the economic aspects of the variable known as a special factor. The model of factor analysis is:

$$
\begin{gathered}
\mathrm{x}_{1}=\mu_{1}+\alpha_{11} f_{1}+\alpha_{12} f_{2}+\ldots+\alpha_{1 m} f_{m}+\varepsilon_{1} \\
\mathrm{x}_{2}=\mu_{2}+\alpha_{21} f_{1}+\alpha_{22} f_{2}+\ldots+\alpha_{2 m} f_{m}+\varepsilon_{2} \\
\ldots \\
\mathrm{x}_{\mathrm{p}}=\mu_{p}+\alpha_{p 1} f_{1}+\alpha_{p 2} f_{2}+\ldots+\alpha_{p m} f_{m}+\varepsilon_{p}
\end{gathered}
$$

Where $\mu_{1}, \mu_{2}, \ldots \mu_{\mathrm{p}}$ are the mean of $\mathrm{x}_{1}, \mathrm{x}_{2}, \ldots \mathrm{x}_{\mathrm{p}} \mathrm{f}_{1}, \mathrm{f}_{2}, \ldots \mathrm{f}_{\mathrm{m}}$ are common factors; $\varepsilon_{1}, \varepsilon_{2}, \ldots \varepsilon_{\mathrm{p}}$ are special factors. $\mathrm{f}_{1}, \mathrm{f}_{2}, \ldots \mathrm{f}_{\mathrm{m}}$ and $\varepsilon_{1}, \varepsilon_{2}, \ldots \varepsilon_{\mathrm{p}}$ are unobservable random variables. $\mathrm{f}_{1}, \mathrm{f}_{2}, \ldots \mathrm{f}_{\mathrm{m}}$ in the expression for economic variables as common factors represent the correlation between the various economic variables of the components. If there is not common factor $\left(\mathrm{j}_{=1,2}, \ldots, \mathrm{m}\right)$ between at least two economic variables, these factors are special factors. Each special factor $\varepsilon_{\mathrm{i}}(\mathrm{i}=1,2, \ldots, \mathrm{p})$ exists only in the expression of the corresponding the $\mathrm{i}$-th single economic variable, and it has only the effect on this economic variable. $\partial_{\mathrm{ij}}$ is called the load of the $\mathrm{i}$-th variable on the

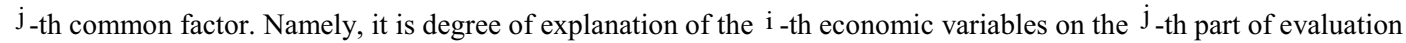
model.

\section{Innovation-driven Strategy of China's Manufacturing Industry Transformation and Upgrading}

At present, the situation is very complex with difficulties and opportunities intertwined. In order to implement innovation-driven development strategy, the country must think highly of strengthening the manufacturing innovation capacity to accelerate the process of China's manufacturing industry transformation and upgrading.

\subsection{The emphasis to promote the transformation and upgrading of manufacturing is focused more on innovation.}

The transformation and upgrading of China's manufacturing industry lie in enhancing the capability of independent innovation. The basic orientation of the transformation and upgrading of Chinese manufacturing industry is to create innovation chain, and build manufacturing innovation chain; it can be started from manufacturing chain to manufacturing innovation chain, and to manufacturing innovation method chain.

In the future, China will still need to take the intelligent manufacturing as the main direction, to accelerate the integration of industrialization and informatization. The implementation of the Internet + advanced manufacturing action plan will promote business model innovation and industry transformation and upgrading, and improve the national manufacturing innovation system as well.

\subsection{Vigorously innovate manufacturing value chain}

In the new era of global technological revolution and industrial transformation, if China's manufacturing industry wants to cross the "trap and high wall", the structural adjustment as well as transformation and upgrading must be conducted smoothly, which requires to innovate the manufacturing value chain, and improve the role of China's manufacturing 
enterprises in the global value chain. The manufacturing development in the future will change from the current mass customization stage to individual development stage. Moreover, the design innovation and technology research and development of manufacturing will become the focus of enterprise development. As a big manufacturing country, China is experiencing the transformation from "Made in China" to "China smart". The product and value can be improved through the combination of industrial design and industrial culture.

\subsection{Create an institutional environment which is conducive to innovation}

If "Made in China" wants to form a new advantage, China must participate in the international competition, so that Chinese enterprises can use extensively international resources, learn from each other, carry out research and development and compete for the market share in the open innovation, as well as further support the system innovation. Companies need to strengthen technological innovation, and strive to carry out the strategy of "mobile Internet +" to achieve interaction between products and culture carried by products with consumers.

\subsection{Build Multi-dimensional Multi-level Manufacturing Industry Collaborative Innovation System}

Innovation is the first driving force of development. In the new era of China's in-depth implementation of the innovation-driven development strategy, the development mode of manufacturing will be shifted from factor-driven to innovation-driven, with the industrial structure optimized and upgraded. In addition, it is inevitable to have mergers and acquisitions, and production concentration. At the same time, the role of emerging industries, services, small and micro enterprises are more prominent, and the small, intelligent and professional production will become a new feature of industrial organization. The country must become a driving force of innovation for the development, deepen reform and opening up, and accelerate the formation of a unified, transparent, orderly, and normative market environment.

Therefore, under the new trend of global technological development and the deep adjustment of industrial competition pattern, it is urgent to conduct the transformation and upgrading of manufacturing industry and the innovation-driven strategy has become the main driving force of this process. Therefore, the transformation and upgrading from government-led innovation to market-oriented enterprise independent innovation can be achieved, which is to promote China to be synonymous with manufacturer of quality from that of quantity.

\section{Conclusion}

Now China is facing a developmental environment to meet with profit and risk, chances and challenges, therefore, we suggest that China should take manufacturing innovation capacity as priority. First of all, put intelligent manufacturing as the main direction, and accelerate the integration of industrialization and informatization. Then, vigorously innovate manufacturing value chain and improving the role of China's manufacturing enterprises in the global value chain. The manufacturing development in the future will change from the current mass customization stage to individual development stage, and design innovation and technology research and development of manufacturing will become the focus of enterprise development. What's more, strengthen technological innovation, and strive to carry out the strategy of "mobile Internet + " to achieve interaction between products and culture carried by products with consumers. Finally, now that, the innovation-driven strategy is the main driving force of China's manufacturing transformation and upgrading, try to achieve conversion of transformation and upgrading from government-led innovation to marketoriented enterprise independent innovation to promote China one of quality from a manufacturer of quantity.

\section{References}

1. R. Nelson. Understanding Technical Change as Evolutionary Process. Amsterdam: North-Holland, (1987)

2. Anderson P, Tushman M. Technological discontinuities and dominant designs: A cyclical model of technological change. Administrative Science Quarterly, 35 (1990)

3. Silverberg G, Lehnert L. Long Waves and Evolutionary Chaos in a Simple Schumpeterian Model of Embodies Technical Change. Structural Change and Economic Dynamics, 9 (1993)

4. J.Niosi, M. Banik. The Evolution and Performance of Biotechnology Regional Systems of Innovation. Cambridge Journal of Economics, 29 (2005)

5. Hedberg, B. L. T.How Organizations Learn and Unlearn.In P.C.Nystrom and W.H.Starbuck. Handbook of Organizational Design, 11 (1981)

6. HousteinH D, NeuwirthE. Longwaves in World Industrial Production, Energy Consumption, Innovations, Inventions, and Patents and Their Identification by Spectral Analysis . Technological Forecasting and Social Change, 22 (1982)

7. Kleinknecht A.Are there Schumpeterian Waves of Innovations, 14 (1990)

8. G - Dosi. Technological Paradigms and Technological Trajectories. Research Policy, 3 (1982)

9. $\mathrm{W} \cdot \mathrm{B} \cdot$ Arthur.Competing Technologies,Increasing Returns, and Lock-in by Historical Events. The Economic Journal, 99 (1989) 
10. G • Dosi.Perspectives on Evolutionary Theory. Science and Public Policy, 6 (1991)

11. Keun Lee, Chaisung Lim. Technological Regimes, catching-up and leap frogging: findings from the Korean Industries. Research Policy, 30 (2001) 